Gazi University
Journal of Science
http://dergipark.gov.tr/gujs

\title{
Effect of Water Cushion on Dynamic Pressures at Impingement Area
}

\author{
Cuneyt YAVUZ* \\ Sirnak University, Civil Engineering Department, 73000 Sirnak, Turkey
}

\section{Highlights}

- This paper focuses on dynamic pressure variations against water cushion at impingement area.

- An experimental study is conducted to define the effectiveness of water cushion for scour prevention.

- An accurate results and dynamic pressure evaluations were obtained.

\begin{tabular}{l} 
Article Info \\
\hline $\begin{array}{l}\text { Received: } 10 / 12 / 2019 \\
\text { Accepted: } 20 / 07 / 2020\end{array}$ \\
Keywords \\
\hline Water jet \\
Dynamic pressure \\
Impact assessment \\
Water cushion \\
Scour
\end{tabular}

\begin{abstract}
A free-fall water jet released from a spillway may cause significant scour on the downstream river reaches due to high dynamic pressures. Energy dissipators are generally used at the downstream of a spillway to disperse the energy of the water jet. In case of low air concentration, the jet may hit the river bed with high dynamic pressure heads that can cause significant scour adjacent to the dam body. The scour can cause significant stability problems on the dam body. To prevent the phenomenon, water cushion can be a practical tool to reduce the jet impact at the impingement area. In this study, the effectiveness of the water cushion is inspected by measuring the dynamic pressure variations against different discharges and varying water cushion levels. The results of the experimental study show that dynamic pressure reduction is reversely proportional to the water cushion level until a certain discharge. Then, water cushion level changes become meaningless, especially for small discharges.
\end{abstract}

\section{INTRODUCTION}

Scour downstream of a dam can be a significant threat to the stability and safety of a dam. The reasons for this phenomenon and its solution means has been investigated through several types of researches [1-8]. Castillo and Carrillo [9] revealed a study about scour, velocity distributions and pressure dispersions produced by a spillway of the Paute-Cardenillo dam in Ecuador. The scour at the downstream of the dam was examined for design discharges of the prototype. They concluded that the scour generated by the jet can be reached up to $21 \mathrm{~m}$ down from the river bed. Bollaert [10] initially investigated the physics of rock which can be broken because of turbulent water jets issued from high-head hydraulic structures. Then, scour formation at the downstream of the hydraulic structure was inspected for scour predictions using nearprototype scaled model namely the Comprehensive Scour Model (CSM). The model has been used to conduct some case studies for comparing the test results with real-life projects. The scour prediction results of CSM show that the model scale may not be directly applicable to the prototypes. Pagliara et al. [11] conducted an experimental study to investigate plunge pool scour depending on various jet parameters. Some empirical equations are proposed to determine water jet design criteria such as impact angle, jet shape, and air content by manipulating test facility and experimental conditions.

In this study, an experimental investigation is conducted to evaluate dynamic pressure variations against changing water cushion levels for six different discharges coming from an uncontrolled spillway. 


\section{EXPERIMENTAL SETUP}

Laleli Dam and HEPP model was used to perform experiments about dynamic pressure variations which are the main reason for scour at the downstream of a spillway (see Figure 1). The model was constructed with 1/25 scale using Froude similarity law. The reservoir was connected to an uncontrolled spillway with an angle of $\alpha_{b}=55^{\circ}$. A fixed circular flip bucket geometry was used during the experiments. The take-off angle selected as $\alpha_{j}=30^{\circ}$. The radius of the flip bucket was $R_{b}=0.60 \mathrm{~m}$. Width of the spillway modelled as $\mathrm{b}=0.80 \mathrm{~m}$ wide rectangular channel.

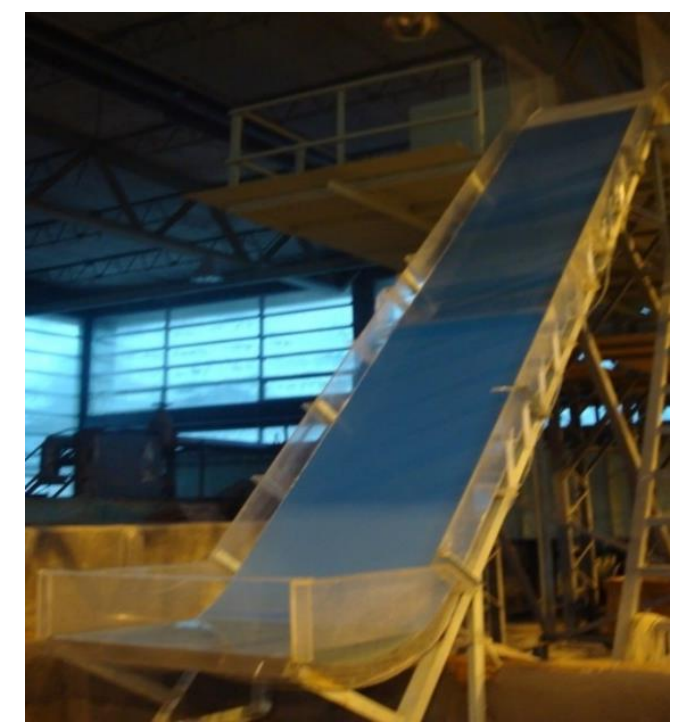

Figure 1. Hydraulic Model

10 Huba (Switzerland) pressure transmitters were employed to record pressure distribution. These transmitters were installed in a $2 \mathrm{~m}$ waterproof plexiglas box and fixed on the ground downstream of the flip bucket (see Figure 2).

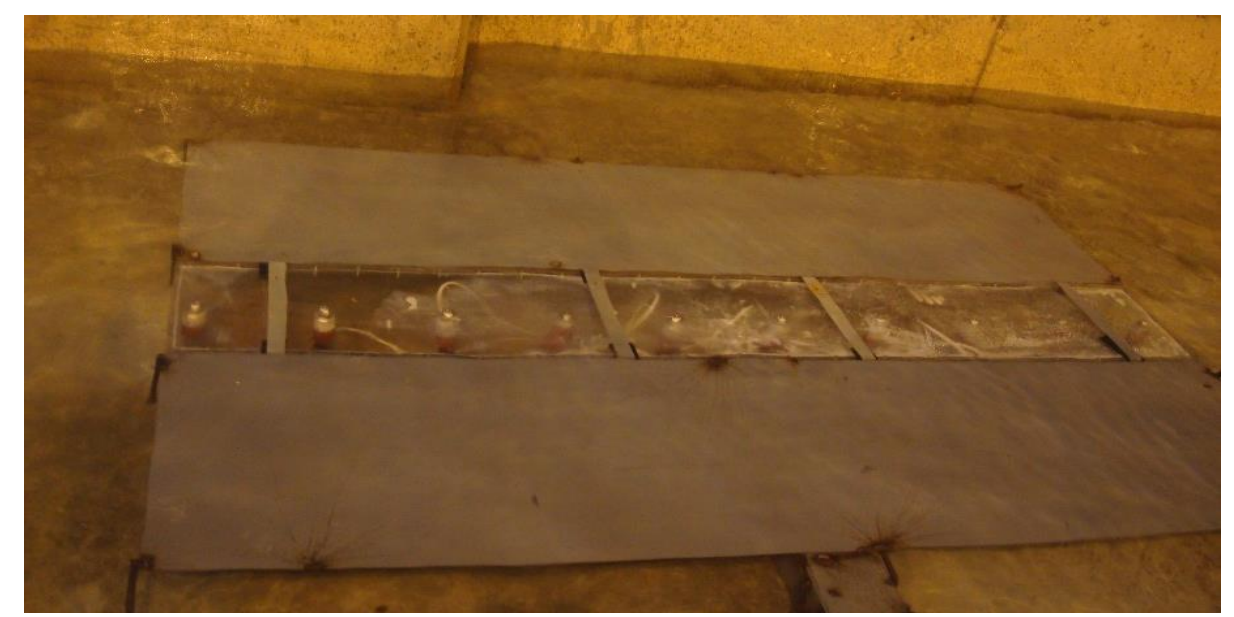

Figure 2. Installment of Pressure transmitters on the channel floor

Each data recorded in using $40 \mathrm{~Hz}$ frequency for 180 second. As a result, 7200 data were analyzed to determine the dynamic pressure distribution on the channel. Once the discharges and tail water level were established, the parameters flow depth, $h_{j}$, velocity of the jet at bucket lip, $V_{j}$, and throw distance at the point the jet strikes the water cushion, $\mathrm{L}$ were set, total pressure variations were recorded at each transmitter from the beginning to the end of the jet impact on the channel bottom. 


\section{METHODOLOGY}

\subsection{Discharge Calculation}

Discharge was calibrated using two control section. One of them was ogee crest located on the upstream of the spillway and the other was a sharp crested weir at the end of $1 \mathrm{~m}$ wide rectangular canal. Sharp crested weir formula was used to determine the discharge for rectangular channels [12]. Discharges were crosschecked according to water levels obtained from the ogee crest and the sharp crested weir located at the end of the experimental facility (see Equations 1-2).

$$
Q=\left(\frac{2}{3}\right) C_{d} b \sqrt{2 g H_{c}{ }^{3}}
$$

where

$$
C_{d}=0.611+0.08\left(\frac{H_{c}}{P}\right)
$$

where $C_{d}$ is the discharge coefficient, $P$ is the height of the crest, $H_{c}$ is the water level above the crest and $b$ is the channel width located at the end of the test facility.

Experiments were conducted for the discharges, $Q, 70,100,130,160,190,220 \mathrm{lt} / \mathrm{s}$. Since the scale of the model was selected as $1 / 25$, the prototype discharge values can be calculated from Froude similarity as $218.8,312.5,406.3,500,593,8$ and $687.5 \mathrm{~m} 3 / \mathrm{s}$. The test program included several experiments. For each discharge, water cushion level was increased from $0.25 \mathrm{~m}$ to $0.75 \mathrm{~m}$ with $0.1 \mathrm{~m}$ interval and same tests were conducted (see Figure 3).

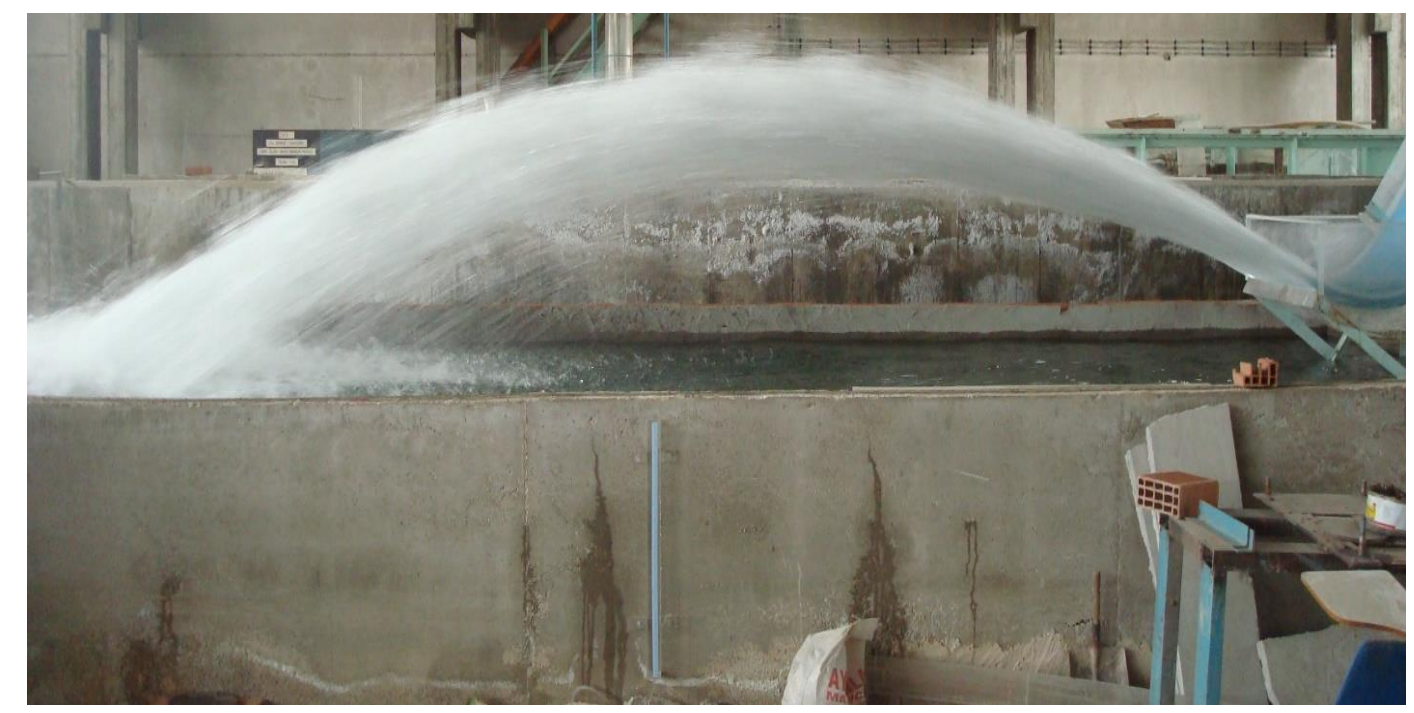

Figure 3. Dispersed jet and water cushion at the impingement area

\subsection{Free Trajectory and Throw}

Generally, trajectory lengths in frictionless domain are calculated using projectile motion theory [13]. Trajectory length in frictionless domain $\mathrm{L}_{\mathrm{t}}$, can be calculated under the action of gravity only. However, air resistance drastically affects throw distance of water jet especially in prototype scale. In this study, trajectory length for each discharge is calculated using Kawakami's equation to define the best location of the pressure transmitters box. Depending on some field investigations, Kawakami [14] proposed an empirical equation to calculate trajectory lengths under air resistance for the prototype scale. He introduced an air resistance coefficient, $\mathrm{k}$ for Equations 3-4; 


$$
\begin{aligned}
& L=\left(\frac{1}{g k^{2}}\right) \ln \left(1+2 k \alpha V_{j} \cos \alpha_{j}\right) \\
& \alpha=\tan ^{-1}\left(k V_{j} \sin \alpha_{j}\right)
\end{aligned}
$$

where $L$ is the throw distance considering air resistance, $k$ is the air resistance coefficient, $V_{j}$ is the velocity at the flip bucket lip, $\alpha_{\mathrm{j}}$ is the water jet angle.

Kawakami [14] also shows empirical relationship both $V_{j}-k$ and $L_{t}-L$ corresponding to various values of $V_{j}$ (see Figure 4). It would be seen that the effect of air resistance is small whenever $V_{j}$ is less than $20 \mathrm{~m} / \mathrm{s}$ but it reduces the throw distance by about $30 \%$ when the velocity is about $40 \mathrm{~m} / \mathrm{s}$.

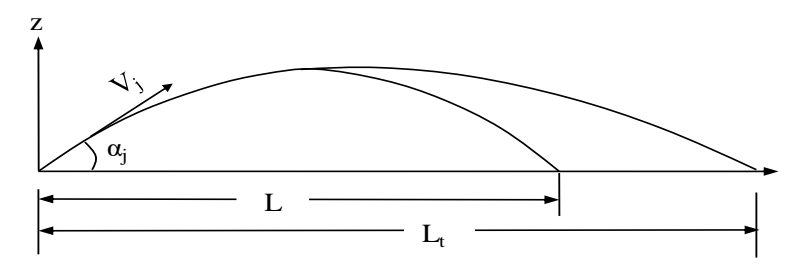

$\mathrm{k}$
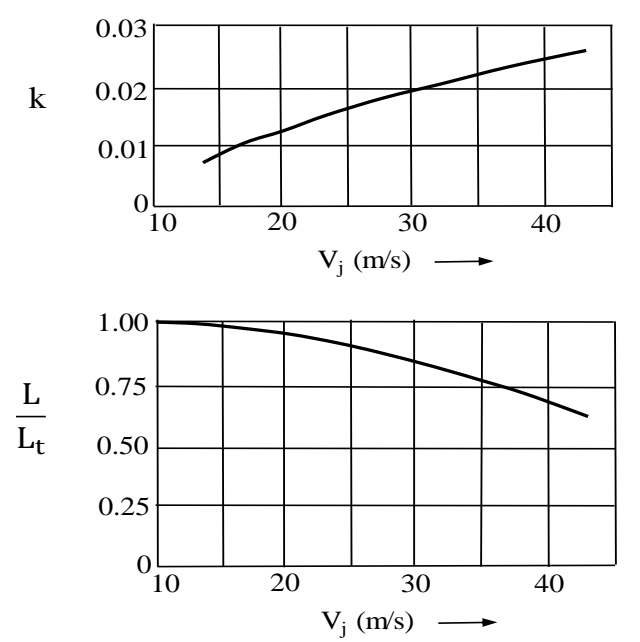

Figure 4. Effect of air resistance on jet trajectory [14]

To calculate trajectory lengths with air entrainment using Equation (3), prototype jet velocities should be calculated benefiting from measured model velocities to obtain correct $k$ values from Figure 4. As we mentioned before, model was constructed by using Froude similarity law. Froude similarity law is

$$
\frac{\left(F_{r}\right)_{m}}{\left(F_{r}\right)_{p}}=\frac{\frac{V_{m}}{\sqrt{g L_{m}}}}{\frac{V_{p}}{\sqrt{g L_{p}}}}=\frac{V_{m}}{V_{p}}=\sqrt{\frac{L_{m}}{L_{p}}}
$$

where $L_{m} / L_{p}=1 / 25$

Using Equation 5., measured model jet velocities are re-calculated for defining prototype jet velocities. By doing so, the air resistance coefficient can be selected from Figure 4 and trajectory lengths with air resistance are calculated accordingly.

\subsection{Dynamic Pressure Measurements}

By fixing the discharge and defining the approximate trajectory location, pressure measurement was performed for different water cushion levels as stated in Section 3.1. Ten pressure transmitters were used to determine the cross-sectional total pressure distribution. A software named as DAQ [15] was used to 
record total pressure values using pressure transmitters. Every pressure transmitter records the total pressure head, $P_{T}$ consists of hydrostatic, $P_{h}$ and hydrodynamic pressure, $P_{d}$ heads. Since the pressure heads are directly recorded by the transmitters, dynamic pressure values can then be calculated by subtracting the hydrostatic pressure heads from recorded total pressure heads

$$
\frac{P_{d}}{\gamma}=\frac{P_{T}}{\gamma}-\frac{P_{h}}{\gamma}
$$

where $P_{d}$ is the dynamic pressure, $P_{T}$ is the total pressure recorded by transmitter, $P_{h}$ is the hydrostatic pressure resulted from the water cushion level, $\gamma$ is the specific weight of water.

Since the recorded pressure values were all positive, average dynamic pressures were determined only averaging the data for each water cushion level.

\section{THE RESEARCH FINDINGS AND DISCUSSION}

\subsection{Discharge Determination}

Discharges used in the tests are calculated using Equation (1). The water level on the sharp-crested weir, $H_{c}$ at the end of the test facility is used to determine required discharge values. Also, water level on the ogee crest, $H_{r}$ connected with the model reservoir is measured to check the correctness of the discharge calculation. 6 different discharge values are selected to perform experiments (see Table 1).

Table 1. Discharge calculation parameters and selected discharges.

\begin{tabular}{|c|c|c|c|c|c|}
\hline$H_{r}(\mathrm{~m})$ & $H_{c}(\mathrm{~m})$ & $P(\mathrm{~m})$ & $C_{d}$ & $\mathrm{~b}(\mathrm{~m})$ & $\mathrm{Q}\left(\mathrm{m}^{3} / \mathrm{s}\right)$ \\
\hline 0.124 & 0.106 & 0.15 & 0.66 & 1.0 & 0.07 \\
\hline 0.157 & 0.135 & 0.15 & 0.68 & 1.0 & 0.10 \\
\hline 0.185 & 0.158 & 0.15 & 0.69 & 1.0 & 0.13 \\
\hline 0.216 & 0.184 & 0.15 & 0.70 & 1.0 & 0.16 \\
\hline 0.236 & 0.20 & 0.15 & 0.71 & 1.0 & 0.19 \\
\hline 0.263 & 0.221 & 0.15 & 0.72 & 1.0 & 0.22 \\
\hline
\end{tabular}

\subsection{Trajectory Length Determination}

Accurate positioning of the pressure transmitters box is vital to get reliable dynamic pressure values using DAQ software. To do so, trajectory lengths are calculated using Equation (3) for each discharge values in advance and the box is positioned accordingly. Related data and calculated trajectory lengths are given in Table 2 .

Table 2. Trajectory length calculation parameters and calculated trajectories.

\begin{tabular}{|c|c|c|c|c|}
\hline$Q\left(\mathrm{~m}^{3} / \mathrm{s}\right)$ & $V_{j}(\mathrm{~m})$ & $\begin{array}{c}k \\
\text { (from the graph) }\end{array}$ & $\alpha_{j}\left({ }^{0}\right)$ & $L(\mathrm{~m})$ \\
\hline 0.22 & 7.86 & 0.025 & 30 & 5.34 \\
\hline 0.19 & 7.66 & 0.0235 & 30 & 5.10 \\
\hline 0.16 & 7.41 & 0.022 & 30 & 4.78 \\
\hline 0.13 & 7.07 & 0.021 & 30 & 4.36 \\
\hline 0.10 & 6.58 & 0.020 & 30 & 3.79 \\
\hline 0.07 & 5.83 & 0.0195 & 30 & 2.98 \\
\hline
\end{tabular}

Since the approximate location of the jet trajectories are defined, dynamic pressure values can be recorded via installed pressure transmitters. 


\subsection{Dynamic Pressure Measurements}

Dynamic pressure values at the downstream of the spillway bucket vary depending on the discharge, air entrainment ratio, turbulence, and water cushion level. In this study, six different discharges are selected, and related dynamic pressure values are recorded according to varying water cushion level. Dynamic pressures for each discharge value are calculated using Equation 6 and shown in Figure 5.

(a)

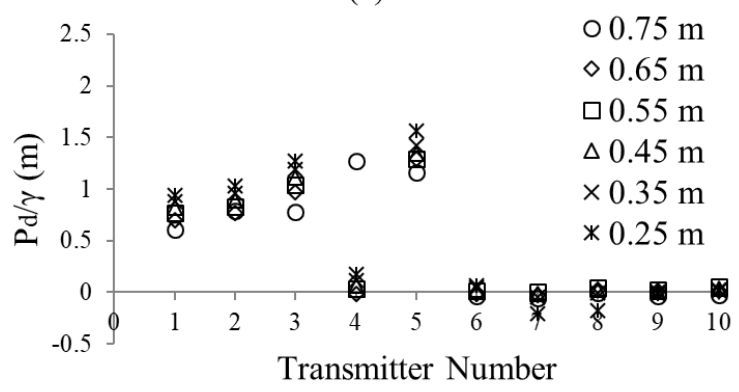

(c)

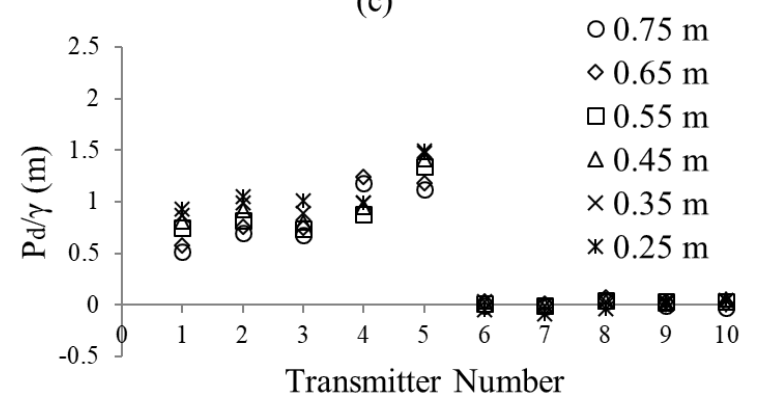

(e)

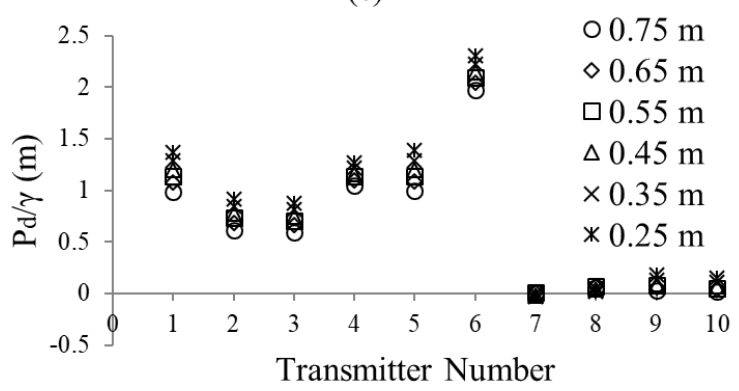

(b)

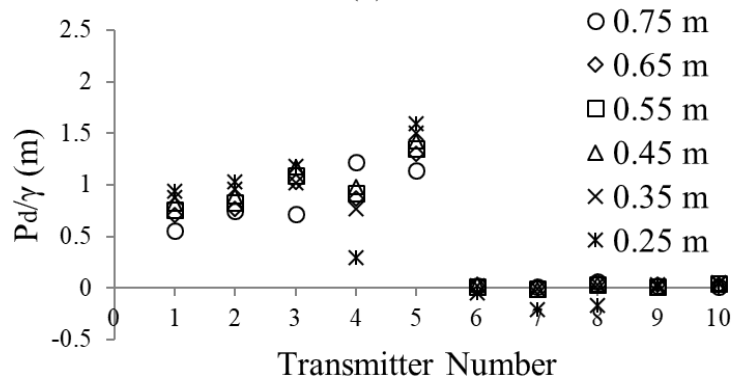

(d)

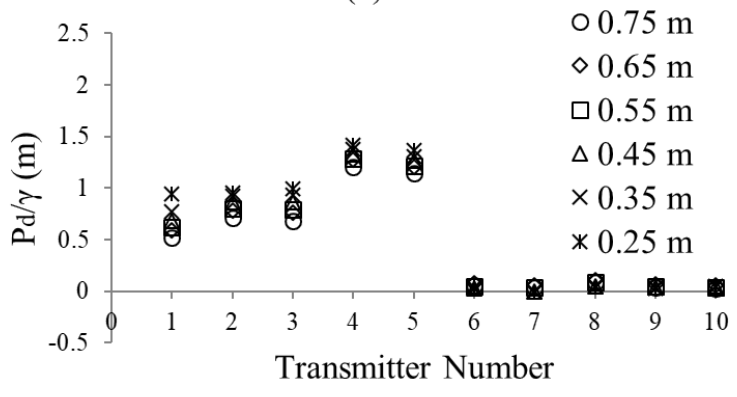

(f)

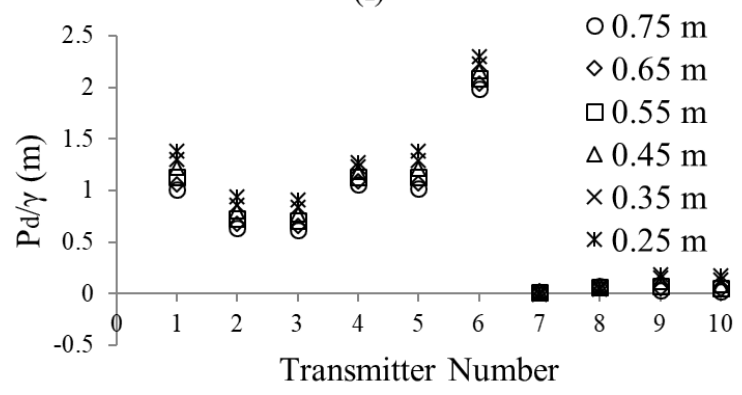

Figure 1. Dynamic pressure values with respect to varying water cushion levels for (a) $0.22 \mathrm{~m} 3 / \mathrm{s}$, (b) $0.19 \mathrm{~m} 3 / \mathrm{s},(c) 0.16 \mathrm{~m} 3 / \mathrm{s},(d) 0.13 \mathrm{~m} 3 / \mathrm{s}$, (e) $0.10 \mathrm{~m} 3 / \mathrm{s}$, and $(f) 0.07 \mathrm{~m} 3 / \mathrm{s}$

By examining the graphs in Figure 5, high dynamic pressure values are observed for low discharges comparing with the higher ones, even if the water cushion level is maximum. Also, we must consider the other phenomena decreasing the impact by increasing the water discharge. This incident may occur due to following reasons;

- There is not enough water flow at the impingement area. Hence, the energy of the jet may not dissipate horizontally.

- When the discharge values getting lower, the air entrainment may not sufficient for energy dispersion of the water jet. So, high dynamic values are recorded for low discharge levels.

- Impingement angle of the water jet for low discharges are getting closer to $90^{\circ}$. Therefore, much more vertical jet impact may generate high dynamic pressure values. 
High discharge values might have resulted in a high level of an air-water mixture that may create a positive effect with water cushion for energy dissipation of the water jets coming from the flip bucket of a spillway.

\section{RESULTS}

Scour downstream of a spillway is one of the most significant issues among the design criteria of dams and hydroelectric power plants. Plunge pools with constant water cushion levels are generally considered as a good solution for design of a dam. Plunge pools are also designed depending on the design discharge of a spillway. However, released water from the spillway varies according to flood conditions and requirements. Therefore, unpredictable dynamic pressures that can cause significant amount of scour might be observed along the river bed.

This study reveals a model study on dynamic pressure variations for different discharges and shows that increasing the water cushion level is not sufficient alone to decrease the impact of the jet on the ground. It can also be concluded that further investigations should be performed to propose a reliable scour prevention method especially for prototypes.

\section{ACKNOWLEDGEMENTS}

This experimental study is conducted on Laleli Dam and Hydroelectric Power Plant model built for DSIM Projects in Middle East Technical University Hydromechanics Laboratory.

\section{CONFLICTS OF INTEREST}

No conflict of interest was declared by the author.

\section{REFERENCES}

[1] Azmathullah, H.M., Deo, M.C., \& Deolalikar P. B., "Neural networks for estimation of scour downstream of a ski-jump bucket", Journal of Hydraulic Engineering, 131(10): 898-908, (2005).

[2] Hoffmans, G.J., "Jet scour in equilibrium phase", Journal of Hydraulic Engineering, 124(4): 430437, (1998).

[3] Hoffmans, G. J., Scour manual, Routledge, (2017).

[4] Mason, P.J., \& Arumugam K., "Free jet scour below dams and flip buckets", Journal of Hydraulic Engineering, 111(2): 220-235, (1985).

[5] Mason, P.J., "Effects of air entrainment on plunge pool scour", Journal of Hydraulic Engineering, 115(3): 385-399 (1989).

[6] Manso, P.A., Bollaert, E.F., \& Schleiss A.J., "Influence of plunge pool geometry on high-velocity jet impact pressures and pressure propagation inside fissured rock media", Journal of Hydraulic Engineering, 135(10): 783-792, (2009).

[7] Melville, B.W., \& Lim S.Y., "Scour caused by 2D horizontal jets", Journal of Hydraulic Engineering, 140(2): 149-155, (2013).

[8] Puertas, J., \& Dolz J., "Plunge pool pressures due to a falling rectangular jet", Journal of Hydraulic Engineering, 131(5): 404-407, (2005).

[9] Castillo, L.G., \& Carrillo J.M., "Scour, velocities and pressures evaluations produced by spillway and outlets of dam", Water, 8(3): 68, (2016). 
[10] Bollaert, E.F., "Physics of rock scour: the power of the bubble". In Scour and Erosion, ASCE Library, 21-40, (2010).

[11] Pagliara, S., Hager, W.H., \& Minor H.E., "Hydraulics of plane plunge pool scour", Journal of Hydraulic Engineering, 132(5): 450-461, (2006).

[12] Bos, M.G., "Discharge measurement structures". Wegeningen: International Institute for Land Reclamation, ILRI, (1989).

[13] Naylor, R.H., "Galileo's theory of projectile motion”, Isis, 71(4): 550-570, (1980).

[14] Kawakami, K., "A study on the computation of horizontal distance of jet issued from ski-jump spillway", In Proceedings of the Japan Society of Civil Engineers, 1973(219): 37-44, (1973).

[15] Data Acquisition (DAQ) Software, Online: http://turkey.ni.com/, (2019). 